\title{
CRAQUEAMENTO TERMOCATALÍTICO DO ÓLEO DE PALMA BRUTO EM ESCALA PILOTO UTILIZANDO O CATALISADOR CARBONATO DE CÁLCIO
}

\author{
D. E. L. LHAMAS ${ }^{1}$, M. C. SANTOS ${ }^{1}$, D. H. S. ABREU ${ }^{1}$, K. S. DIAS ${ }^{2}$, E. R. L. LIMA ${ }^{2}$, F. T. S. \\ B. OLIVEIRA ${ }^{1}$, N. T. MACHADO ${ }^{2}$, L. E. P. BORGES ${ }^{3}$ \\ ${ }^{1}$ Universidade Federal do Pará, Pós-Graduação em Engenharia de Recursos Naturais \\ ${ }^{2}$ Universidade Federal do Pará, Faculdade de Engenharia Química \\ ${ }^{3}$ Instituto Militar de Engenharia, Química \\ E-mail para contato: dyennyufpa@yahoo.com.br
}

\begin{abstract}
RESUMO- $O$ presente trabalho tem como objetivo estudar o craqueamento termocatalítico do óleo de palma bruto em escala piloto na presença do catalisador carbonato de cálcio visando à obtenção de biocombustíveis alternativos aos combustíveis fósseis. O óleo de palma bruto e o produto líquido orgânico (PLO) obtidos do craqueamento termocatalítico foram caracterizados por análises de índice de acidez, índice de saponificação, índice de refração, viscosidade, densidade, cromatografia e espectroscopia no infravermelho, além das análises de ponto de fulgor, corrosividade e resíduo de carbono para o produto líquido orgânico. A análise do espectro de infravermelho do produto líquido orgânico indicou a presença de hidrocarbonetos, tais como alcanos, alcenos e compostos oxigenados como ácidos carboxílicos, cetonas e alcoóis, os quais foram confirmados pela análise cromatográfica. Portanto, o catalisador carbonato de cálcio demonstrou atuar no processo de craqueamento secundário, no qual os ácidos graxos se decompõem originando hidrocarbonetos.
\end{abstract}

\section{INTRODUÇÃO}

A maior parte de toda energia consumida no mundo provém de combustíveis derivados do petróleo, os chamados combustíveis fósseis. Essa forma de produção de energia não é desejável em termos sustentáveis por se tratar de uma fonte esgotável e principalmente devido à contribuição destes combustíveis com a poluição ambiental, apontado como o maior colaborador para o aumento das mudanças climáticas provocadas pelo efeito estufa (Lima et al., 2004).

O desenvolvimento de fontes alternativas de energia, que sejam renováveis, é um assunto de suma importância, e tem sido amplamente pesquisado com a finalidade de diminuir a dependência dos combustíveis fósseis. Há também a crescente preocupação com a preservação do meio ambiente, devido aos danos sofridos com o aumento dos níveis de poluentes, notadamente pelo gás carbônico. $\mathrm{O}$ $\mathrm{CO}_{2}$ é considerado o maior responsável pelo efeito estufa, em parte pela contribuição das emissões de gases pelos motores movidos a combustíveis fósseis (Bonomi et al., 2006).

Dentre as fontes de energia derivadas de biomassa que têm atraído muita atenção estão os óleos 


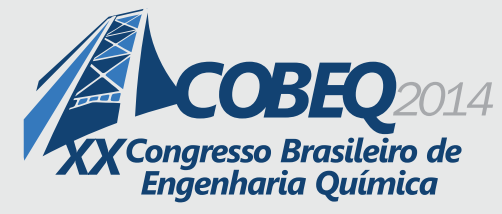

19 a 22 de outubro de 2014

Florianópolis/SC

vegetais, a gordura animal e os resíduos graxos. Por se tratarem de fontes renováveis de energia, vários estudos têm sido desenvolvidos na tentativa de utilizar estas matérias-primas como alternativa para a produção tanto de óleos combustíveis bem como lubrificantes (Prado, 2009).

No entanto, o uso de óleos vegetais in natura em motores do ciclo diesel é limitado por algumas propriedades físicas dos mesmos, principalmente sua baixa volatilidade, sua alta viscosidade e seu caráter poliinsaturado, que implicam em alguns problemas nos motores. Dentre estes, destacam-se a formação de depósitos de carbono por combustão incompleta e a atomização ineficiente e/ou entupimento dos sistemas de injeção (Ma e Hanna, 1999; Ramos et al., 2003).

Diferentes alternativas vêm sendo consideradas, a fim de buscar o desenvolvimento de metodologias de transformações químicas dos óleos vegetais, para que suas propriedades se tornem mais adequadas ao seu uso como combustível (Prado, 2009). Das diversas rotas tecnológicas investigadas tem-se destacado o processo de craqueamento termocatalítico de matérias-primas derivadas de ácidos graxos. Esse processo parece ser um método simples e eficiente para a produção de biocombustíveis, uma vez que apresenta flexibilidade de matérias-primas, visto que podem ser utilizadas desde óleos in natura, gorduras, óleos residuais e subprodutos.

O processo de craqueamento ou pirólise é um processo térmico, catalítico ou não, constituído fundamentalmente de uma reação de quebra (cracking) das cadeias carbônicas de triésteres de origem animal ou vegetal pelo aumento da temperatura do sistema, resultando em uma mistura de compostos constituída, em sua maioria, por hidrocarbonetos lineares de diferentes pesos moleculares (Ma e Hanna, 1999). Uma desvantagem desse processo é a acidez do produto final obtido, devido principalmente à presença dos ácidos carboxílicos na mistura (Suarez et al., 2007).

Neste contexto o presente trabalho tem como objetivo realizar o craqueamento termocatalítico do óleo de palma (Elaeis guineensis) bruto em escala piloto, utilizando o catalisador carbonato de cálcio, objetivando a obtenção de um biocombustível consoante com os padrões especificados pela Agência Nacional do Petróleo (ANP), Gás Natural e Biocombustíveis.

\section{MATERIAIS E MÉTODOS}

\subsection{Matéria-prima}

A matéria-prima utilizada neste trabalho foi o óleo de palma (Elaeis guineenses, Jacq) bruto, fornecido pela empresa ENGEFAR LTDA (Levilândia, Ananindeua, Pará) e usado como recebido. $\mathrm{O}$ catalisador utilizado foi o carbonato de cálcio $\left(\mathrm{CaCO}_{3}\right)$, extra leve, B. Herzog, o qual foi seco em estufa a uma temperatura de $120^{\circ} \mathrm{C}$ por 2 horas.

\subsection{Craqueamento Termocatalítico do Óleo de Palma}

O processo de craqueamento do óleo de palma foi realizado em uma planta piloto de craqueamento termocatalítico (THERMTEK/FEQ/UFPA), conforme mostra a Figura 1. Nessa planta o óleo de palma foi craqueado em regime de batelada na presença do catalisador carbonato de cálcio. 
O procedimento experimental consistiu inicialmente na pesagem do catalisador $(10 \% \mathrm{em}$ relação à massa de óleo), o qual foi introduzido no reator por uma abertura circular na parte inferior. Posteriormente pesou-se uma massa de $50 \mathrm{~kg}$ de óleo de palma bruto, a qual foi acondicionado em um tanque de polietileno com formato cilíndrico e capacidade de $200 \mathrm{~L}$. Em seguida, fixou-se a temperatura de operação em $440{ }^{\circ} \mathrm{C}$, sob agitação constante de $150 \mathrm{rpm}$.

O óleo contido no tanque foi bombeado para um trocador de calor com forma geométrica cilíndrica de aço inoxidável e aquecimento por resistência elétrica com potência de $15 \mathrm{~kW}$. Após atingir a temperatura de $200{ }^{\circ} \mathrm{C}$, o óleo foi direcionado para o reator de craqueamento de aço inoxidável com forma geométrica cilíndrica, com sistema de agitação mecânica e capacidade de 125L de operação. O tempo nesta etapa foi de 40 minutos. Após o início do craqueamento, os produtos sob a forma gasosa foram condensados utilizando o condensador multitubular acoplado à saída do reator de craqueamento. O tempo para iniciar o craqueamento foi de $2 \mathrm{~h}$ e 14 minutos. Os gases não condensáveis formados durante a reação foram conduzidos numa tubulação de aço para serem queimados numa tocha. $\mathrm{O}$ tempo total do processo foi de 4 h e 35 minutos. $\mathrm{O}$ produto obtido denominado de produto líquido orgânico (PLO) foi submetido a uma filtração a vácuo para posteriormente ser caracterizado.

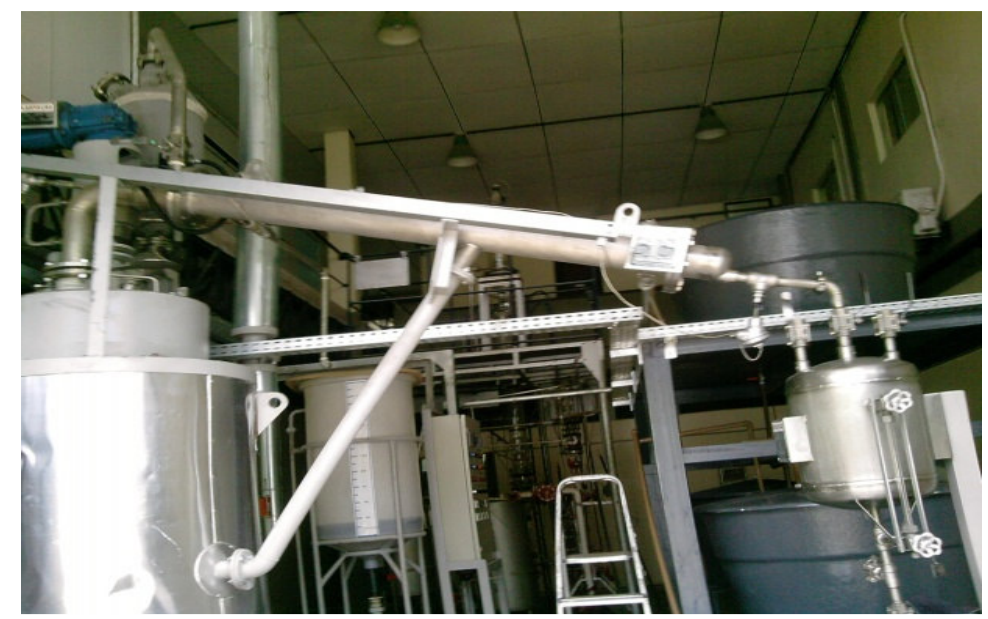

Figura 1-Planta piloto de craqueamento termocatalítico.

\subsection{Caracterização físico-química do óleo de palma e do produto líquido orgânico}

As análises físico-químicas para o óleo de palma bruto foram realizadas de acordo com as normas da AOCS (American Oil Chemists' Society) e as análises do produto líquido orgânico de acordo com as especificações da ANP $\mathrm{N}^{\circ} 65$ para o diesel de petróleo. Para o óleo de palma e o produto líquido orgânico foram realizadas análises de viscosidade, densidade, índice de saponificação, índice de refração e índice de acidez. Além destas análises foram realizadas para o PLO as análises de corrosividade, ponto de fulgor e resíduo de carbono.

O óleo de palma bruto e o produto líquido foram analisados por espectros de absorção na região de infravermelho IR (Shimadzu, Modelo: Prestige 21), no Laboratório de Química do Instituto 


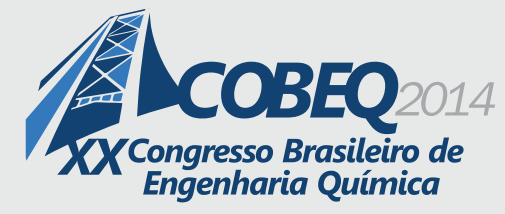

19 a 22 de outubro de 2014

Florianópolis/SC

Militar de Engenharia (IME/ Rio de Janeiro). Os espectros de absorbância foram obtidos no intervalo de 4000 a $400 \mathrm{~cm}^{-1}$, com resolução de $16 \mathrm{~cm}^{-1}$ e com auxílio de uma janela de $\mathrm{KBr}$. A análise cromatográfica para o PLO foi realizada no Instituto Militar de Engenharia (IME-RJ) no equipamento Agillent Technologies - Modelo 7890 A, coluna: supelcowax 30m x 0,25mm, pressão: $14,485 \mathrm{psi}$, fluxo na coluna $0,9 \mathrm{~mL} / \mathrm{min}$, temperatura do injetor $300{ }^{\circ} \mathrm{C}$. $\mathrm{O}$ forno permaneceu a $75^{\circ} \mathrm{C}$ por $1 \mathrm{~min}$, em seguida foi aquecido até $240{ }^{\circ} \mathrm{C}$ numa taxa de $12,5^{\circ} \mathrm{C} / \mathrm{min}$ e foi mantido a $240{ }^{\circ} \mathrm{C}$ por 5,8 min. Os detectores utilizados foram espectrômetro de massa FID.

A análise cromatográfica para o óleo de palma bruto foi realizada no Laboratório de Química da Universidade Federal do Pará utilizando um cromatográfico com auto-injetor CP 3800 Variam, equipado com Detector de Ionização de Chama (FID), apresentando as seguintes características: coluna capilar CP WAX $52 \mathrm{CB}$ com $30 \mathrm{~m}$ de comprimento, $0,32 \mathrm{~mm}$ de diâmetro interno e $0,25 \mu \mathrm{m}$ de filme. O gás Hélio foi utilizado como fase móvel, na razão de $1,0 \mathrm{~mL} / \mathrm{min}$. A programação de temperatura usada foi de $80^{\circ} \mathrm{C}$ por $2 \mathrm{~min}$., taxa $10^{\circ} \mathrm{C} / \mathrm{min}$ e temperatura de $180^{\circ} \mathrm{C}$ por $1 \mathrm{~min}$, taxa de $10^{\circ} \mathrm{C} / \mathrm{min}$, temperatura de $250^{\circ} \mathrm{C}$ por $5 \mathrm{~min}$. A solução de referência continha padrões de ésteres metílicos.

\section{RESULTADOS E DISCUSSÕES}

\subsection{Características Físico-Químicas}

A Tabela 1 apresenta os resultados das características físico-químicas do óleo de palma bruto e do produto líquido orgânico, sendo os resultados comparados com os valores da ANVISA e da ANP $\mathrm{N}^{\mathrm{o}} 65$ para diesel de petróleo, respectivamente. De acordo com os resultados obtidos para o óleo de palma bruto constatou-se concordância aos valores especificados pela resolução da ANVISA, com exceção aos índices de refração e saponificação. Entretanto, faz-se importante ressaltar que as características físico-químicas dos óleos dependem de alguns fatores, tais como, as condições do terreno em que a oleaginosa foi plantada e as condições em que o produto foi armazenado. $\mathrm{O}$ resultado da viscosidade de $46,25 \mathrm{~mm}^{2} \mathrm{~s}^{-1}$ para o óleo de palma bruto foi bastante elevado, comparado com o resultado do PLO, o que inviabiliza o seu uso direto como combustível. Este resultado justifica a necessidade do processo de craqueamento termocatalítico, visando à redução e adequação deste parâmetro junto à norma vigente para o combustível fóssil.

Com relação aos resultados das características físico-químicas do PLO, verificou-se que a densidade está dentro das especificações da ANP No 65 para diesel de petróleo. Nesse caso, não há restrição quanto à densidade para a utilização do PLO em motores diesel. Entretanto, a viscosidade apresentou discordância com a norma, problema provavelmente causado pela quantidade de ácidos graxos livres formados na quebra das moléculas de triglicerídeos. O índice de acidez de 22,60 mg $\mathrm{KOH} / \mathrm{g}$ foi relativamente baixo quando comparado com dados da literatura, como por Ribeiro (2006) que obteve valores de índice de acidez de $139,1 \mathrm{mgKOH} / \mathrm{g}$ para o craqueamento térmico e 77,2 $\mathrm{mgKOH} / \mathrm{g}$ para o craqueamento termocatalítico e de Quirino (2006) com índices de 112,64 mgKOH/g para o craqueamento térmico e $75,53 \mathrm{mgKOH} / \mathrm{g}$ para o craqueamento termocatalítico.

O parâmetro de índice de refração do PLO não apresentou mudanças significativas quando 


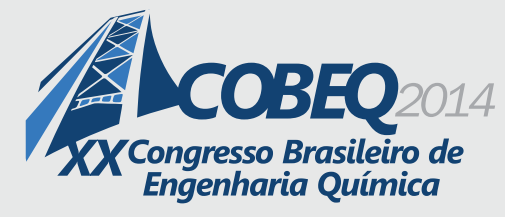

comparado com o óleo de palma bruto, mostrando que o processo de craqueamento não alterou esse parâmetro. $\mathrm{O}$ resultado obtido para o ponto de fulgor apresentou valor de $28^{\circ} \mathrm{C}$, abaixo do mínimo especificado pela ANP que é de $38^{\circ} \mathrm{C}$, provavelmente explicado pela presença de hidrocarbonetos leves $\mathrm{C}_{5}-\mathrm{C}_{7} . \mathrm{O}$ resultado da corrosividade está em acordo com as especificações estabelecidas pela ANP. O resultado do resíduo de carbono apresentou-se acima do valor especificado pela ANP, evidenciando que o PLO obtido é rico em carbono, se apresentando como desvantagem, pois dificulta a queima e leva à formação de fuligem e depósitos de carbono.

Embora algumas propriedades do PLO se encontrem fora das especificações da ANP, tais resultados podem ser amenizados com uma separação de misturas por destilação, de forma, a obter frações nas faixas de ebulição dos principais combustíveis derivados do petróleo e assim apresentar-se como uma alternativa viável para utilização como biocombustível líquido similar ao diesel.

Tabela 1 - Resultados das características físico-químicas do óleo de palma e do PLO

\begin{tabular}{|c|c|c|c|c|}
\hline Características & $\begin{array}{c}\text { Óleo de palma } \\
\text { bruto }\end{array}$ & $\begin{array}{c}\text { ANVISA } \\
(2005)\end{array}$ & $\begin{array}{c}\text { Produto } \\
\text { Líquido }\end{array}$ & $\begin{array}{c}\text { ANP N } \\
65,(2011)\end{array}$ \\
\hline Índice de Acidez $(\mathrm{mgKOH} / \mathrm{g})$ & 3,46 & 10 & 22,60 & - \\
\hline Índice de saponificação $(\mathrm{mgKOH} / \mathrm{g})$ & 256,2 & $190-209$ & 47 & - \\
\hline Índice de Refração & 1,46 & $1,454-1,456$ & 1,45 & - \\
\hline Viscosidade $\left(\mathrm{mm}^{2} \mathrm{~s}^{-1}\right)$ & 46,25 & - & 5,21 & $2-4,5$ \\
\hline Densidade $\left(\mathrm{kg}^{3} \mathrm{~m}^{3}\right)$ & 893 & $0,89-0,89$ & 826 & $820-850$ \\
\hline Corrosividade & - & - & $1 \mathrm{a}$ & $1 \mathrm{a}$ \\
\hline Ponto de Fulgor $\left({ }^{\circ} \mathrm{C}\right)$ & - & - & 28 & 38 \\
\hline Resíduo de carbono $(\%)$ máx & 0,42 & 10 & 0,42 & 0,25 \\
\hline
\end{tabular}

\subsection{Espectros de Infravermelho}

A Figura 2 mostra os espectros de infravermelho do produto líquido orgânico e do óleo de palma bruto, cuja identificação das bandas foi realizada com base na literatura de Silverstein, et al., (2007). A comparação entre os espectros de infravermelho das duas amostras mostra claramente a transformação da matéria-prima original (triglicerídeo) no produto do craqueamento (ácido graxo). Esta diferença pode ser observada pelo desaparecimento da banda em $1743 \mathrm{~cm}^{-1}$ característica da presença de carbonilas de ésteres nos triglicerídeos e o aparecimento da banda $1712,61 \mathrm{~cm}^{-1}$ característica de carbonilas de ácidos graxos.

O espectrograma de infravermelho do PLO apresenta vibração na região de $3500 \mathrm{~cm}^{-1}$ e 2500 $\mathrm{cm}^{-1}$ que é atribuída ao estiramento do grupo hidroxila $\mathrm{O}-\mathrm{H}$ dos dímeros dos ácidos carboxílicos. Segundo Silverstein et al., (2007), o estreitamento nesta faixa do espectro evidencia a diminuição de compostos oxigenados. Verifica-se também a presença de bandas na região $2852,71 \mathrm{~cm}^{-1}$ e 2922,15 $\mathrm{cm}^{-1}$ associadas às deformações axiais de alifáticos referentes aos estiramentos $\mathrm{C}-\mathrm{H}$ de $\mathrm{CH}_{2}$ e $\mathrm{CH}_{3}$. Há também ocorrência das bandas 1466,94 $\mathrm{cm}^{-1}$ e $1375,24 \mathrm{~cm}^{-1}$, referentes à presença de alcanos $\mathrm{CH}_{2}$ e $\mathrm{CH}_{3}$ e a banda de $1649,42 \mathrm{~cm}^{-1}$, entre $1667-1640 \mathrm{~cm}^{-1}$ indicando alcenos $\mathrm{C}=\mathrm{C}$, além da banda de $964,40 \mathrm{~cm}^{-1}$, entre $970-960 \mathrm{~cm}^{-1}$, referentes à deformação axial da ligação $\mathrm{C}=\mathrm{C}$, presença da banda 


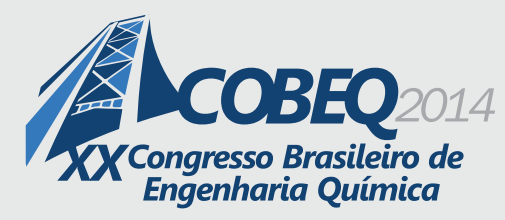

903,52 $\mathrm{cm}^{-1}$, indicando vibrações de deformação angular fora do plano de C-H. Observa-se a presença da banda em $729,44 \mathrm{~cm}^{-1}$ referente à deformação angular assimétrica no plano, $\mathrm{CH}_{2}$. Em suma pode-se observar que no espectro do PLO houve a formação de hidrocarbonetos, tais como alcanos (parafínicos), alquenos (olefínicos) e alquinos, confirmado na análise cromatográfica.

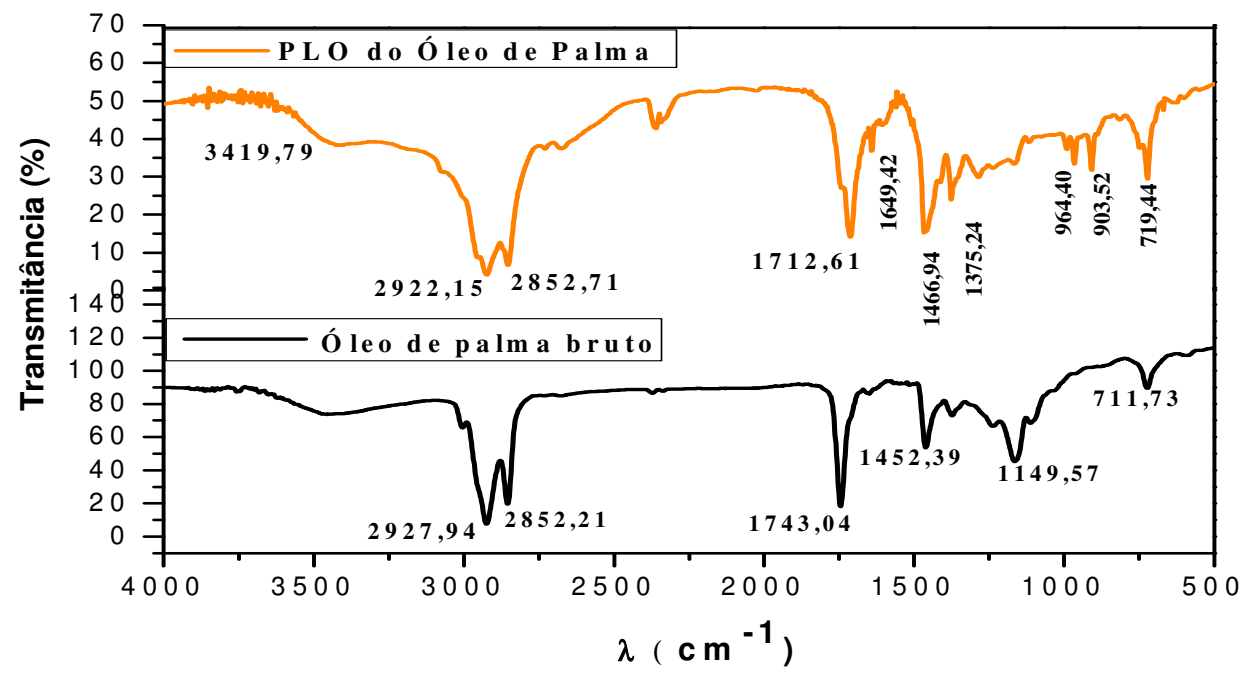

Figura 2-Espectro do produto líquido orgânico e do óleo de palma bruto.

\subsection{Resultados da Cromatografia}

A Figura 3 mostra o cromatograma do óleo de palma bruto, o qual evidencia altas concentrações de ácido oleico $(43,12 \%)$ e palmítico $(36,62 \%)$, apresentando equivalência na composição com a literatura, com percentagem maior de C18:1 e C16:0.

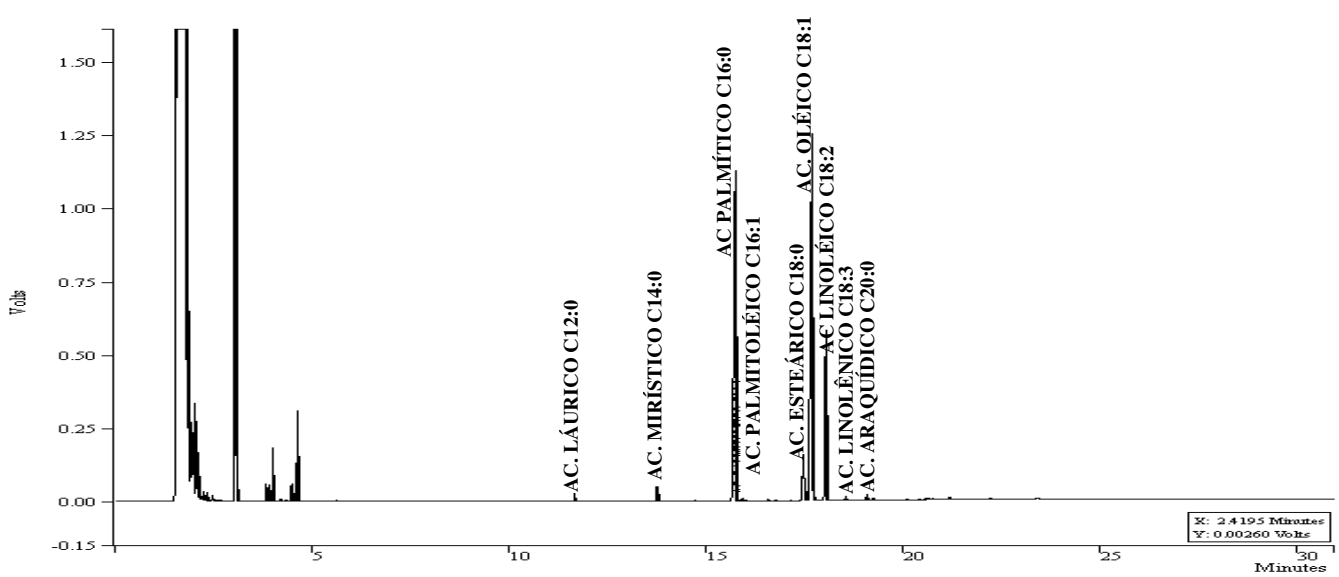

Figura 3- Cromatograma do óleo de palma bruto.

O resultado da análise cromatográfica do PLO bruto obtido no processo de craqueamento termocatalítico está representado na Figura 4. O cromatograma confirma a presença de ácidos 


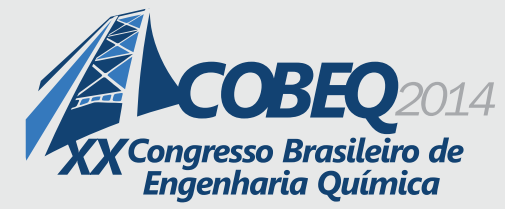

Engenharia Química
19 a 22 de outubro de 2014

Florianópolis/SC

carboxílicos e outros compostos oxigenados, como grupos carbonila e/ou hidroxila, além de diversos hidrocarbonetos saturados, olefinícos e naftenícos. Analisando os resultados dos compostos presentes na Tabela 2, verificaram-se maiores porcentagens de hidrocarbonetos $(63,34 \%)$ e menores porcentagens de compostos oxigenados $(36,66 \%)$. Portanto, o resultado da composição do PLO utilizando $10 \%$ de $\mathrm{CaCO}_{3}$ apresentou resultados promissores no que concerne a desoxigenação do produto do craqueamento.

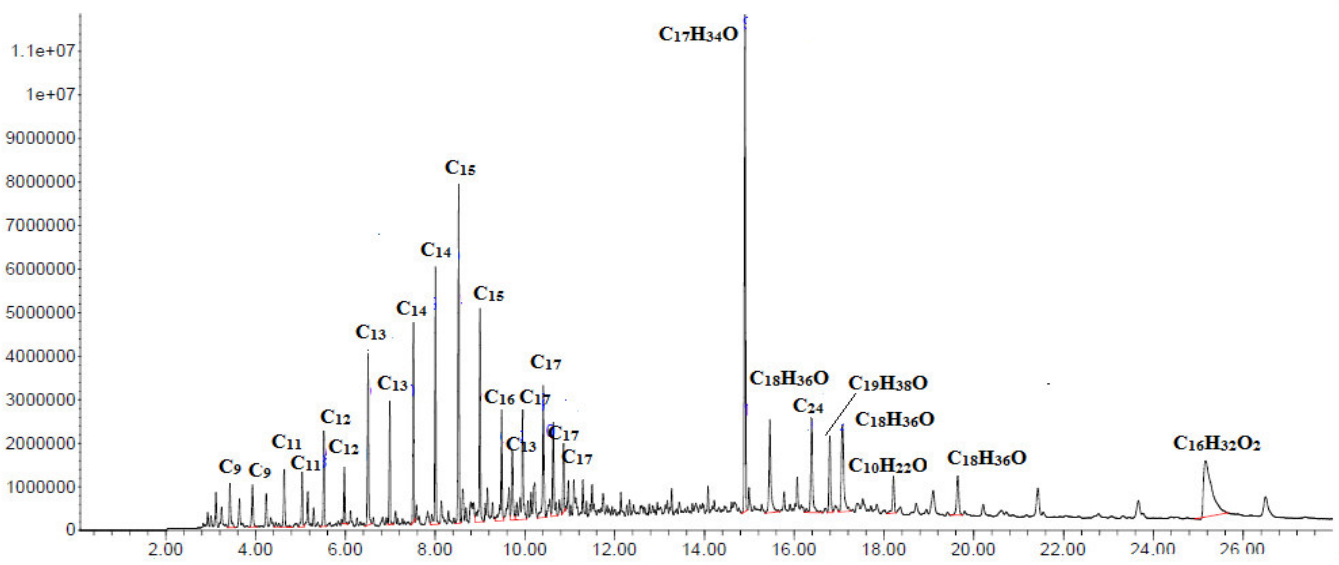

Figura 4-Cromatograma do produto líquido orgânico.

Tabela 2- Composição dos produtos presentes no PLO

\begin{tabular}{|c|c|}
\hline Compostos & Composição (\%) no PLO \\
\hline Parafínicos & 31,11 \\
\hline Olefínicos & 24,52 \\
\hline Naftênicos & 7,71 \\
\hline Total de Hidrocarbonetos & 63,34 \\
\hline Acidos graxos & 9,95 \\
\hline Alcoois & 6,21 \\
\hline Cetonas & 20,50 \\
\hline Total de Compostos oxigenados & 36,66 \\
\hline
\end{tabular}

\section{CONCLUSÃO}

O produto líquido orgânico apresentou resultado satisfatório em termos de índice de acidez, quando comparado com a literatura, embora algumas propriedades físico-químicas estejam fora das especificações da ANP. Tais resultados podem ser amenizados com a realização do processo de destilação, e, assim o produto pode-se apresentar como uma alternativa viável para utilização como biocombustível líquido similar ao diesel seja em substituição, ou misturado a este.

A análise por espectrometria de infravermelho permitiu identificar os principais grupos funcionais presentes na estrutura molecular do produto líquido orgânico, sendo observados compostos 


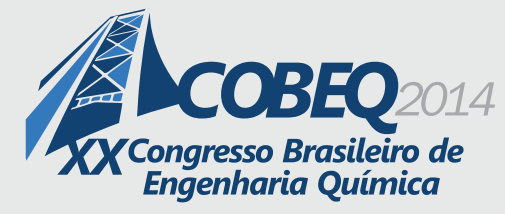

19 a 22 de outubro de 2014

Florianópolis/SC

oxigenados (ácidos carboxílicos, cetonas e álcoois), hidrocarbonetos parafínicos (alcanos) e hidrocarbonetos olefínicos (alquenos), os quais foram confirmados pela análise de GC-MS. A análise cromatográfica permitiu a identificação da composição do PLO bruto que apresentou maiores porcentagens de hidrocarbonetos $(63,34 \%)$ e menores porcentagens de compostos oxigenados $(36,66 \%)$. O catalisador carbonato de cálcio promoveu a desoxigenação do produto do craqueamento, favorecendo ao processo de craqueamento secundário e originando produtos ricos em hidrocarbonetos.

\section{REFERÊNCIAS}

ANP - Agência Nacional de Petróleo, Gás Natural e Biocombustíveis. Resolução no 65, de 06 de novembro de 2011. Diário Oficial da União, Brasília, DF.

AOCS - American Oil Chemists Society, 5ed. Champaign, 2001.

BRASIL. Resolução RDC ANVISA/MS nº. 270, de 22 de setembro de 2005. Regulamento técnico para óleos vegetais, gorduras vegetais e creme vegetal. Diário Oficial da União, Brasília, DF, 23 set. 2005. Seção 1.

BONOMI, A.; POÇO, J. G. R.; TRIELLI, M. A. Biocombustíveis - A solução brasileira para uma matriz energética sustentável. Revista Brasileira de Engenharia Química, Outubro, 2006.

LIMA, D.G., SOARES, V.C.D., RIBEIRO, E.B., CARVALHO, D.A., CARDOSO, E.C.V., RASSI, F.C., MUNDIM, K.C., RUBIM, J.C., SUAREZ, P.A.Z., Diesel-like fuel obtained by pyrolysis of vegetableoils, Journal of Analytical and Applied Pyrolysis, v. 71, p.987-996, 2004.

MA, F.; HANNA, M. A. Biodiesel production: a review. Bioresource Tecnology, v. 70, p. 1-15, 1999.

PRADO, C. M. R. Produção e Caracterização de Biocombustíveis por Craqueamento de Óleos Vegetais via Catálise com Bauxita. 2009. Dissertação (Mestrado em Química). Universidade Federal de Goiás. Goiânia, 2009.

QUIRINO, R. L.. Estudo do efeito da presença de alumina dopada com $\mathrm{TiO}_{2}$ e $\mathrm{ZrO}_{2}$ no craqueamento do óleo de soja. 2006. 58 f. Dissertação (Mestrado em Química)- Universidade de Brasília. Brasília, 2006.

RAMOS, LP; DOMINGOS, A.K.; KUCEK, K.T.; WILHELM,H.M. Biodiesel: Um projeto de sustentabilidade econômica e sócio-ambiental para o Brasil. Biotecnologia:Ciência $e$ Desenvolvimento, v.31, p.28-37, 2003.

RIBEIRO, E. B. O. O estudo da desoxigenação do produto de craqueamento catalítico de óleo de mamona (Ricinus communis) na presença de diversos catalisadores. 2006. 58 f. Dissertação (Mestrado em Química). Universidade de Brasília, Brasília. 2006.

SILVERSTEIN, R. M.; WEBSTER, F. X.; KIEMLE, D. J. Identificação espectrométrica de compostos orgânicos. Rio de Janeiro: Livros Técnicos e Científicos, 2007.

SUAREZ, P. A. Z.; MENEGHETTI, S. M. P.; MENEGHETTI, M. R. Transformação de Triglicerídeos em Combustíveis, Materiais Poliméricos e Insumos Químicos: Algumas Aplicações da Catálise na Oleoquímica. Química Nova, v. 30, n. 3, p. 667-676, 2007. 